\title{
Lagged influence of North Atlantic Oscillation on population dynamics of a Mediterranean terrestrial salamander
}

\section{Sebastiano Salvidio, Fabrizio Oneto, Dario Ottonello \& Mauro V. Pastorino}

International Journal of Biometeorology

ISSN 0020-7128

Int J Biometeorol

DOI 10.1007/s00484-015-1028-4

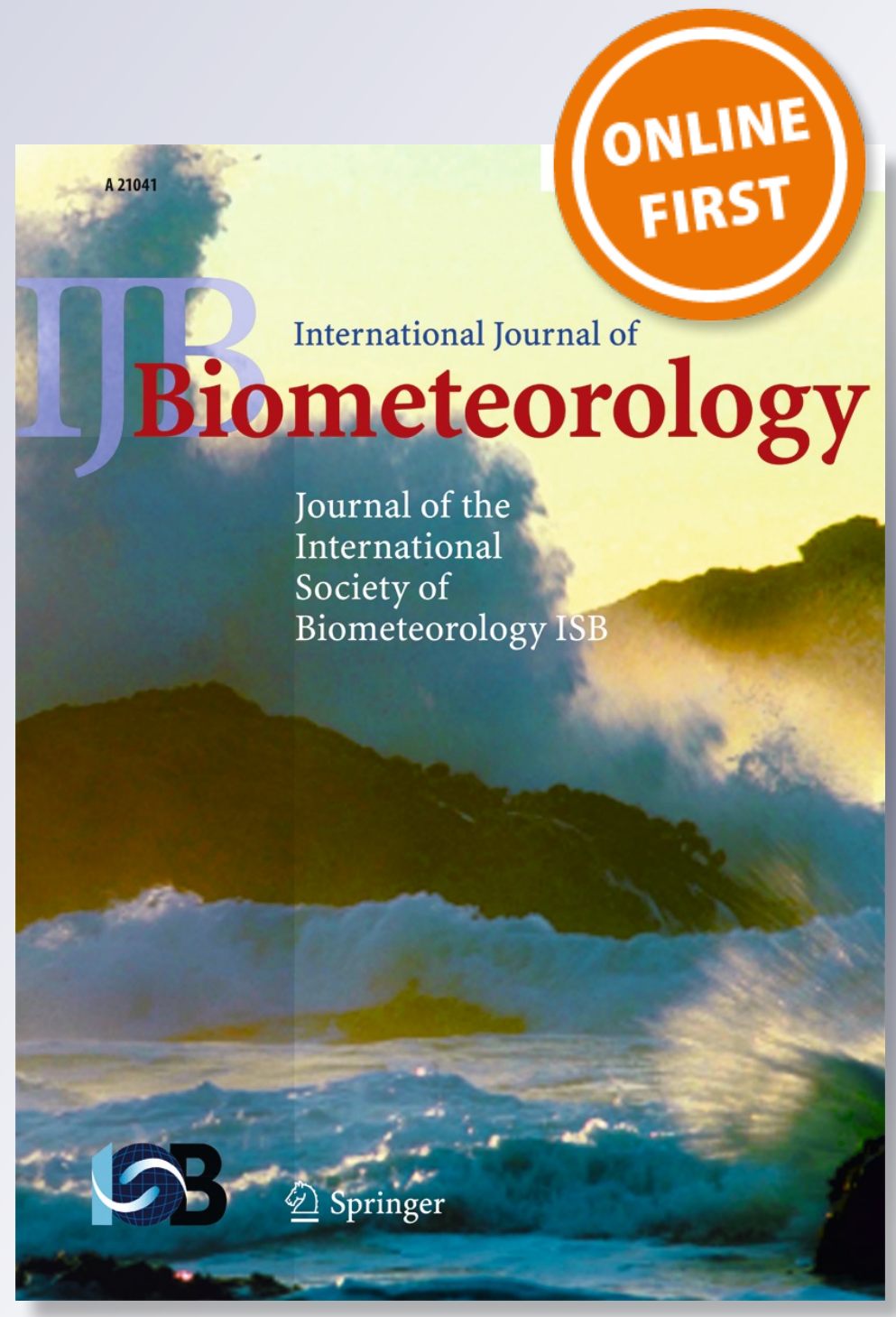

留 Springer 
Your article is protected by copyright and all rights are held exclusively by ISB. This eoffprint is for personal use only and shall not be self-archived in electronic repositories. If you wish to self-archive your article, please use the accepted manuscript version for posting on your own website. You may further deposit the accepted manuscript version in any repository, provided it is only made publicly available 12 months after official publication or later and provided acknowledgement is given to the original source of publication and a link is inserted to the published article on Springer's website. The link must be accompanied by the following text: "The final publication is available at link.springer.com". 


\title{
Lagged influence of North Atlantic Oscillation on population dynamics of a Mediterranean terrestrial salamander
}

\author{
Sebastiano Salvidio $^{1,2}$ (D) Fabrizio Oneto ${ }^{1,2} \cdot$ Dario Ottonello $^{3} \cdot$ Mauro V. Pastorino $^{2}$
}

Received: 23 December 2014 / Revised: 13 June 2015 / Accepted: 14 June 2015

(C) ISB 2015

\begin{abstract}
The North Atlantic Oscillation (NAO) is a largescale climatic pattern that strongly influences the atmospheric circulation in the northern Hemisphere and by consequence the long-term variability of marine and terrestrial ecosystem over great part of northern Europe and western Mediterranean. In the Mediterranean, the effects of the NAO on vertebrates has been studied mainly on bird populations but was rarely analysed in ectothermic animals, and in particular in amphibians. In this study, we investigated the relationships between winter, spring and summer NAO indexes and the long-term population dynamics of the plethodontid salamander Speleomantes strinatii. This terrestrial salamander was monitored inside an artificial cave in NW Italy for 24 consecutive years. The relationships between seasonal NAO indexes and the salamander dynamics were assessed by cross-correlation function (CCF) analysis, after prewhitening the time series by autoregressive moving average statistical modelling. Results of CCF analyses indicated that the salamander abundance
\end{abstract}

Sebastiano Salvidio

salvidio@dipteris.unige.it

Fabrizio Oneto

oneto.fabrizio@alice.it

Dario Ottonello

dario.ottonello@studionatura.net

Mauro V. Pastorino

mvpastor@tiscali.it

1 Dipartimento di Scienze Della Terra Dell'Ambiente e Della Vita (DISTAV), Università di Genova, Corso Europa 26,

I-16132 Genova, Italy

2 Gruppo Speleologico Ligure "Arturo Issel”, Villa Comunale ex Borzino, Casella Postale 21, I-16012 Busalla (GE), Italy

3 Dipartimento di Scienze Ambientali, Informatica e Statistica, Università Cà Foscari, Campo Della Celestia, 30122 Venezia, Italy varied in relation to the one-year ahead winter NAO $(P=$ 0.018 ), while no relationships were found with spring and summer indexes. These results strengthen some previous findings that suggested a high sensitivity of temperate terrestrial amphibians to wintertime climatic conditions.

Keywords Amphibians · ARMA · Cross-correlation function $\cdot$ Mediterranean $\cdot$ Underground habitat $\cdot$ Winter climate

\section{Introduction}

The North Atlantic Oscillation (NAO) is a global climatic index that describes the temporal variability in the atmospheric pressure measured along a north-south gradient, from the subpolar region of Iceland to the Azores in the subtropical part of the North Atlantic Ocean (Hurrell 1995; Hurrell and van Loon 1997; Stenseth et al. 2003). The differences in atmospheric pressure determine the direction and speed of the westerly winds that cross the Atlantic Ocean, blowing from North America towards Europe. As a consequence, the NAO affects the quantity and strength of the weather storms that hit the northern regions of the European subcontinent and the western areas of the Mediterranean basin (Hurrell 1995). The effects of the NAO on local weather are observable throughout the year, but this index shows its greatest level of variability during wintertime, when the air masses that cross the Atlantic embed their highest energy content (Stenseth et al. 2003). For these reasons, the NAO is mainly considered a winter climatic index, although it may influence weather conditions of western Europe (Hurrell and van Loon 1997; Stenseth et al. 2003) and the Mediterranean basin (Rubolini et al. 2007; Cañellas et al. 2010) all over the year. 
In the Mediterranean, the influence of the NAO on local weather has been demonstrated in relation to air and sea temperatures, precipitations and river discharges (e.g. Quadrelli et al. 2001; Forchhammer and Post 2004; Brandimarte et al. 2011), with a strength that is highest in the western part of the basin and becomes weaker in the easternmost areas (LópezMoreno et al. 2011). Usually in southern Europe, positive values of the winter NAO index are associated with cold and dry weather conditions, while the opposite (i.e. rainy and warm weather) is observed during prevalent negative NAO years (Stenseth et al. 2003; Brandimarte et al. 2011).

A recent review by Gordo et al. (2011) summarised the known ecological effects of NAO index on marine and terrestrial ecosystems in the Mediterranean. Taking into account only terrestrial ecosystems, the NAO direct influence has been clearly demonstrated on the growth rate and phenology of several flowering plants and trees and also on the annual yield of different crops of economic interest (Gordo et al. 2011). Concerning terrestrial vertebrates, the majority of the studies assessed the influence of the NAO fluctuations on the phenology, dynamics, abundance and migration patterns of bird populations. For example water birds, such as ducks and flamingos, increase their ranges or population densities in southern France during rainy periods, when winter NAO values are in general negative (e.g. Almaraz and Amat 2004; Béchet and Johnson 2008).

In the case of Mediterranean ectothermic terrestrial vertebrates, and in particular of amphibians, only one study explicitly investigated the effects of the NAO on population dynamics (Bosch et al. 2007). In this study, a positive relationship between increasing temperature, driven by positive NAO values, was associated with the spread of the amphibian parasitic chythrid fungus Batrachochitrium dendrobatidis (Bosch et al. 2007). This phenomenon caused amphibian mass mortalities and the local decline of the populations of the common toad Bufo bufo in high-elevation areas of central Spain (Bosch et al. 2007).

In the present study, the relationships between different NAO indexes and the long-term time series of the terrestrial salamander Speleomantes strinatii were analysed through their cross-correlation function (CCF), a statistical approach commonly used to highlight the possible time-lagged dependence between two variables of interest, while estimating the strength of their association (Brockwell and Davies 2002; Probst et al. 2011). Winter, spring and summer NAO indexes were used to evaluate their influence on salamander dynamics in relation to its reproduction cycle. In fact, during winter, females lay and attend egg clutches and newborn are recruited into the population (Oneto et al. 2010), while in spring and summer, salamanders feed actively on their invertebrate prey both in surface habitats (Salvidio et al. 2012) and in underground environments (Salvidio et al. 1994).

\section{Materials and methods}

\section{Study species and site}

S. strinatii is a medium size (total length $<115 \mathrm{~mm}$ ) completely terrestrial salamander belonging to the family Plethodontidae (Lanza 2007). The species is endemic to southern France and north-western Italy and is found on humid rock faces, in the forest leaf litter along streams and also in underground habitats, where it may reach high population densities (Lanza 2007). S. strinatii is a long-lived salamander that may attain 10-12 years of age (Lindstrom et al. 2010). It is active aboveground during mild and wet periods and retreats underground during the coldest months of the year and during dry and hot summers (Salvidio 1993). During wintertime, females lay directly on the soil a relatively small number of eggs (usually $8-13$ ) that are actively defended against possible predators (Salvidio et al. 1994; Oneto et al. 2010).

The study site is a horizontal artificial tunnel that develops about $35 \mathrm{~m}$ underground at $369 \mathrm{~m}$ a.s.l. in the municipality of Savignone (province of Genova, NW Italy). This cave was excavated during World War II as an air-raid shelter with originally two entrances. However, one of them collapsed before the beginning of the study and is now completely sealed. The site is not connected to a wider karstic system but is probably connected to the epigean environment by fractures and crevices. Since 1986, the remaining cave entrance was closed by an iron gate and the tunnel used as a biospelological station dedicated to study of the resident cave salamander population. Underground air temperatures and relative humidity vary seasonally in synchrony with the surface climate. In this site, the biological community is composed mainly by flies, spiders and salamanders that all display a clearly seasonal pattern of activity, with a maximum in July and a minimum in February (Salvidio et al. 1994).

\section{Validation of the salamander population index}

Salamanders active on the cave walls were counted in July during a 2-h sampling period, from 1990 to 1995. Beginning in 1996, the absolute population abundance was also estimated by a three-sample temporary removal experiment (White et al. 1982). Removals were obtained every other day and all captured individuals were caged inside the cave and released unharmed at the end of the third sampling (i.e., within $96 \mathrm{~h}$ ). Removal data were analysed by model $\mathrm{M}_{\mathrm{bh}}$ in CAPTURE software (White et al. 1982). This model assumes a closed population, constant capture efforts and removal of a relevant proportion of the population during each sampling occasion (Williams et al. 2001). The first removal sample was obtained with the same procedure used to count salamanders in the period 1990-1995, allowing the comparison between the methods. In all years, the removal assumptions were fulfilled, 
and capture probabilities were relatively high (mean $0.60 \pm$ $0.02 \mathrm{SE}, \mathrm{N}=18$ ) and without significant variations among years (Friedman non-parametric RM ANOVA, $S=20.57$, $d f=17, P=0.196$ ). The level of variability, expressed through the coefficient of variation $(\mathrm{CV})$, was similar between the two series; the count index had $\mathrm{CV}=0.29(95 \%$ bootstrapped $\mathrm{CI}=$ $0.24-0.36, N=24)$ while the $\mathrm{CV}$ of the estimated abundance was 0.23 (95\% bootstrapped $\mathrm{CI}=0.19-0.30, N=18)$. Moreover, the salamander abundance and the count index shared similar trajectories (Fig. 1); thus, the population index was considered a good proxy for the salamander population absolute abundance and used with confidence in time-series analyses.

\section{NAO seasonal indexes and time-series analyses}

The normalised station based winter (December-March), spring (April-June) and summer (July-September) NAO indexes were used in analyses (all data sets downloaded from https://climatedataguide.ucar.edu/climate-data).

The lagged correlations between NAO indexes and cave salamander population dynamics were assessed by the application of the statistical framework used by Probst et al. (2011), in which an external "pressure" is cross-correlated to a biological "state". Because autocorrelation and trend in the time series may cause spurious results and misleading conclusions (Royama 1992; Probst et al. 2011), the residuals obtained through autoregressive moving average (ARMA) modelling (Chatfield 2004), estimated through maximum likelihood, were used in cross-correlations. Therefore, time series were tested for autocorrelation by the analysis of the autocorrelation function $(A C F)$ and for trend by difference sign test (Brockwell and Davies 2002). Akaike's information criterion corrected for small samples $\left(\mathrm{AIC}_{\mathrm{c}}\right)$ was used in model selection. In addition, residuals were tested for autocorrelation by the Liung-Box and McLeod-Li portmanteau tests and for randomness by the turning point test (Brockwell and Davies 2002). Finally, the strength of AR and MA coefficients was estimated by the ratio: estimated autoregressive coefficient $/(1.96 \times s e)$. If this ratio was $<1$ in absolute value, then the coefficient was considered non-significantly different from zero and the model discarded (Brockwell and Davies 2002: 408). ARMA modelling and cross-correlation analyses were performed by means of the software "Iterative Time series Modelling" (ITSM2000, Brockwell and Davies 2002).

\section{Results}

During the 24-year study period, the salamander population counts varied from 33 in 2008 to 93 in 2000 and displayed a rather regular pattern of fluctuation (Fig. 1). The ACF displayed a well-defined wave pattern (inset in Fig. 1), with a first non-significant positive maximum at lag $15\left(A C F_{15}=0.241, P=0.29\right)$ and a statistically significant minimum at lag $8\left(A C F_{8}=-0.556, P<0.05\right)$. This regular but asymmetric pattern corresponds to the definition of "weak evidence for statistical periodicity" given by Turchin (2003: 181).

The two best fitting ARMA models, according to their $\operatorname{AIC}_{c}$, were $\operatorname{ARMA}(2,1)$ and ARMA $(3,0)$ (Table 1). However, only the former fulfilled all the diagnostic criteria (Table 1). The ARMA $(2,1)$ model suggests that both direct and delayed density dependence were interacting with an autocorrelated
Fig. 1 Time-series plots of Speleomantes strinatii. Circles: salamanders counts (1990-2013); squares: estimated abundances with $95 \%$ confidence limits (1996-2013). The inset shows the autocorrelation function $(A C F)$ of the salamander time series with $95 \%$ confidence bands (horizontal stippled lines)

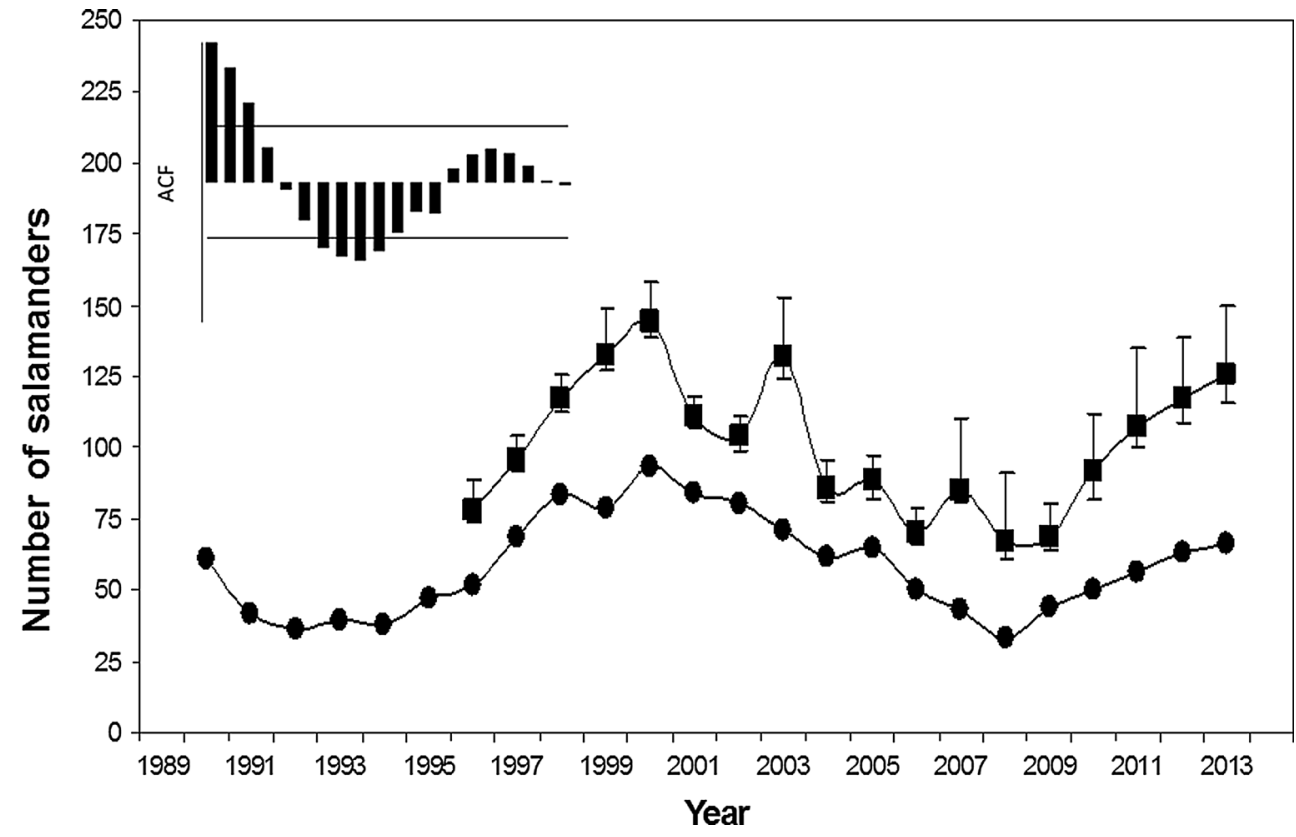


Table 1 ARMA modelling of Speleomantes strinatii time series

\begin{tabular}{|c|c|c|c|c|c|}
\hline Model & $K$ & $\mathrm{AIC}_{\mathrm{C}}$ & $\Delta \mathrm{AIC}_{\mathrm{C}}$ & Residual analysis & ARMA coefficients non-significantly $\neq 0.0$ \\
\hline $\operatorname{ARMA}(2,1)$ & 4 & -17.76 & -17.76 & All tests n.s. & \\
\hline $\operatorname{ARMA}(3,0)$ & 4 & -16.98 & -16.98 & All tests n.s. & $\operatorname{AR}(2)$ \\
\hline $\operatorname{ARMA}(2,2)$ & 5 & -15.52 & -15.52 & All tests n.s. & $\operatorname{MA}(2)$ \\
\hline $\operatorname{ARMA}(3,1)$ & 5 & -14.94 & -14.94 & All tests n.s. & $\operatorname{AR}(2), \operatorname{AR}(3)$ \\
\hline $\operatorname{ARMA}(0,3)$ & 4 & -14.73 & -14.73 & $\mathrm{QML}=44.19, P=0.014$ & \\
\hline $\operatorname{ARMA}(2,0)$ & 3 & -14.47 & -14.47 & $\mathrm{QML}=34.22, P=0.025$ & \\
\hline $\operatorname{ARMA}(1,2)$ & 4 & -14.36 & -14.36 & $\mathrm{QML}=42.03, P=0.027$ & \\
\hline $\operatorname{ARMA}(2,3)$ & 6 & -13.34 & -13.34 & All tests n.s. & $\operatorname{MA}(2), \operatorname{MA}(3)$ \\
\hline $\operatorname{ARMA}(1,0)$ & 2 & -12.87 & -12.87 & $\mathrm{QLB}=42.26, P=0.016$ & \\
\hline $\operatorname{ARMA}(1,1)$ & 3 & -12.19 & -12.19 & $\mathrm{QML}=30.96, P=0.029$ & MA(1) \\
\hline $\operatorname{ARMA}(3,2)$ & 6 & -12.13 & -12.13 & All tests n.s. & $\operatorname{AR}(2), \operatorname{AR}(3), \operatorname{MA}(1), \operatorname{MA}(2)$ \\
\hline $\operatorname{ARMA}(1,3)$ & 5 & -11.51 & -11.51 & $\mathrm{QML}=34.99, P=0.020$ & $\mathrm{MA}(1), \mathrm{MA}(2), \mathrm{MA}(3)$ \\
\hline $\operatorname{ARMA}(0,2)$ & 3 & -9.16 & -9.16 & All tests n.s. & \\
\hline $\operatorname{ARMA}(3,3)$ & 7 & -8.40 & -8.40 & All tests n.s. & $\operatorname{AR}(2), \operatorname{MA}(2)$ \\
\hline $\operatorname{ARMA}(0,1)$ & 2 & -4.41 & -4.41 & $\mathrm{QLB}=54.84, P=0.001 ; \mathrm{TP}, P=0.029$ & \\
\hline $\operatorname{ARMA}(0,0)$ & 1 & 48.32 & 48.32 & $\mathrm{QLB}=95.76, P=0.001 ; \mathrm{QML}=52.15, P=0.001 ; \mathrm{TP}, P=0.043$ & \\
\hline
\end{tabular}

$A I C_{C}$ Akaike's information criterion corrected for small samples, $K$ number of parameters, $n$.s. non-significant, $Q L B$ Liung-Box test for autocorrelation, $Q M L$ Mc Leod-Li test for autocorrelation, TP turning point test for randomness

stochastic factor in the regulation of the cave salamander dynamics (Royama 1992).

The variability the different NAO indexes used in the study is illustrated in Fig. 2, while the results of the time-series statistics are resumed in Table 2. There was evidence for autocorrelation in the spring index (Table 2), while the winter and summer NAOs could be not be distinguished from white noise (all tests, $P>0.05$, Table 2), at least during the 24-year time frame considered. Therefore, only the spring NAO index was prewhitened by the application of ARMA modelling, while spring and summer NAO indexes were used in $\mathrm{CCF}$ analysis untransformed.

When the residuals from the ARMA $(2,1)$ model of the salamander time series were cross-correlated with the climatic variables, only in one case there was evidence of statistical significance: this was the one-year lagged winter NAO index that displayed a significant negative correlation (Fig. 2, cross-correlation $=0.621$, $P=0.018)$.
Fig. 2 Cross-correlation function (CCF) between Speleomantes strinatii prewhitened time series and winter NAO index.

Horizontal stippled lines are the $95 \%$ confidence bands

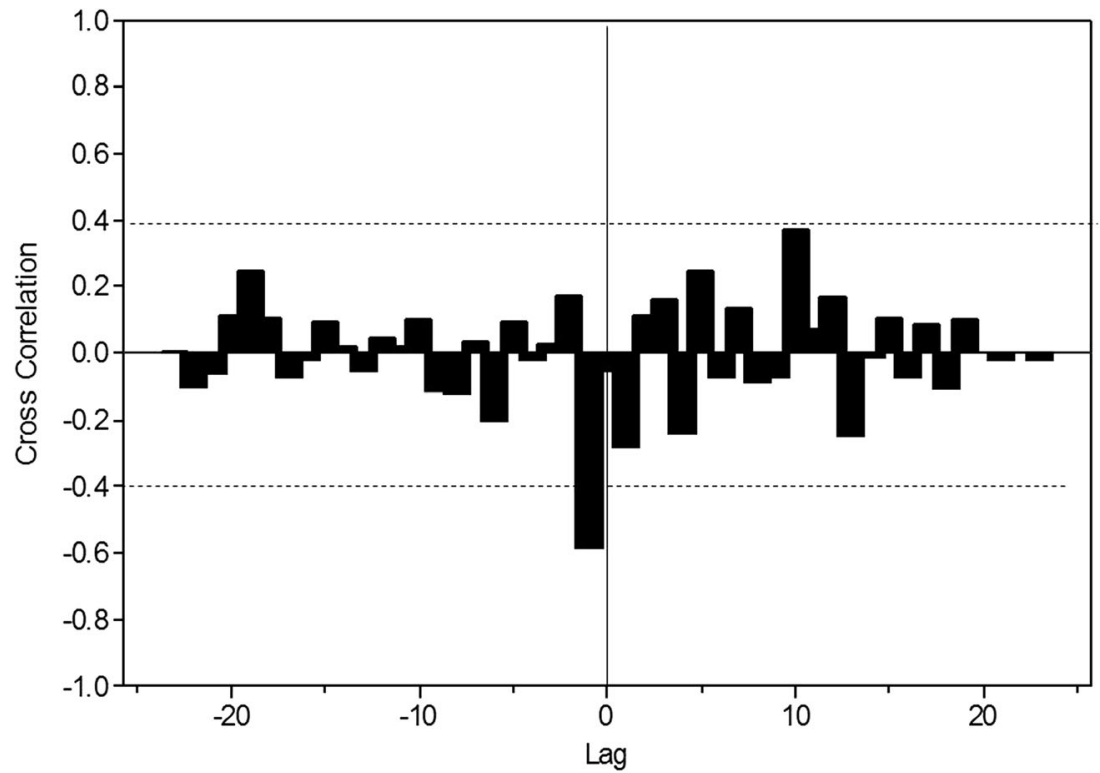


Table 2 Tests for trend and autocorrelation of the seasonal NAO indexes used in crosscorrelation function (CCF) analyses

\begin{tabular}{llll}
\hline Index & Turning point test & Differences & \\
\hline Sign test & Model selected for CCF analysis & & \\
NAO winter & $P=0.401$ & $P=0.299$ & Untransformed time series \\
NAO spring & $P=0.029$ & $P=0.729$ & ARMA(1,0) residuals \\
NAO summer & $P=0.737$ & $P=0.298$ & Untransformed time series \\
\hline
\end{tabular}

\section{Discussion}

The main finding of this study is the presence of a significant lagged relationship between the winter NAO climate index and the long-term population dynamics of the terrestrial salamander S. strinatii. Conversely, no relation was found between the salamander abundance and both spring and summer NAO indexes. These results were not unexpected because there is some evidence that amphibian populations are regulated by wintertime weather conditions, at least in temperate ecosystems (Reading 2007; Salvidio 2007). The statistical approach used in this study seems relatively robust against the possibility of observing nonsense correlations (sensu Yule 1926) often obtained when autocorrelated or trending variables are correlated (Royama 1992). In addition, the CCF analysis identified and measured the 1-year ahead lagged structure of correlation existing between the environmental pressure and the population dynamics. This procedure seems particularly fruitful when interpreting the dynamical fluctuations of age-structured populations, such as the focal one, in which the same environmental factor may affect with different strength different demographic age groups that may be characterised by different levels of sensitivity (e.g. Yoccoz and Gaillard 2006). The interplay between climate and density dependence in age-structured populations is complex and may lead to high levels of unpredictability, depending on the structure of density dependence and also on the frequency of extreme climatic events (e.g. Coulson et al. 2008). In the $S$. strinatii population, the negative winter NAO values that are indicators of humid and warm weather in the Mediterranean (Stenseth et al. 2003) may have increased the salamander survival in particular of eggs, newborn or first year juveniles, all of these stages being small-size and therefore highly sensitive to unfavourable dry weather conditions (Hairston 1987).

Although the results of the present study highlighted the significant effect of winter climate on the salamander's dynamics on the basis of correlation analysis and not of experimental evidence, they confirm two other similar studies (Warren and Bradford 2010; Salvidio 2007). Both studies were performed in temperate forest ecosystems, the southern Appalachian Mountains of North America (Warren and Bradford 2010) and the northern Italian Apennines (Salvidio 2007). These regions share similar seasonal climate patterns, in which during the coldest months, the salamanders retreat underground where they remain inactive and do not feed until the following spring, when the availability of their main prey (i.e. leaf-litter invertebrates) increases together with temperature and moisture, all factors that maximise the time salamanders spend foraging on the forest floor (Salvidio 1993; Petranka 1998: 16). Plethodontids are lungless salamanders that rely entirely on cutaneous respiration for gas exchange and water metabolism (Wells 2007). Therefore, they are particularly sensitive to environmental conditions that limit their above ground activities and influence also their metabolic intake (Caruso et al. 2014). Actually, Warren and Bradford (2010) found similar negative correlations between the winter NAO and Desmognathus salamander abundance in the southern Appalachians. In North America, the amount of winter rainfall increases during positive NAO phases suggesting again that dry winters may reduce Desmognathus salamander abundance. Overall, this result should not be surprising because there is growing evidence that in temperate regions of the northern Hemisphere, the winter climate is the main environmental factor that regulates the long-term dynamics of amphibians (e.g. Reading 2007; Griffiths et al. 2010).

Finally, another relevant consequence of this study concerns the future ecological consequences of the observed relationship between winter NAO and salamander population abundance. In fact, the NAO index is strongly related to the climate change at the global level (Hurrell 1995; Forchhammer and Post 2004). Therefore, the salamander dynamics, although apparently stationary during the 24-year study period, will be driven in the future by global variations in winter climate more than suspected, especially if a high frequency of dry winters will produce a negative trend in the salamander ecological dynamics over the long-term. The capability of $S$. strinatii to adapt to directional climatic variations is unknown, but if the species will not be able to cope with the unfavourable climatic trend, populations will begin to decline in the more drier parts of the Apennines and in particular in the Mediterranean coastal habitats.

Acknowledgments The Italian Ministry of Environment MATTM issued captures permits in all years (DPN-2010-0010807 for 2010-13). Thanks are due to the Speleological Group "A. Issel” for granting a continuous access to the study site and to the Province of Genova administration for having secured the cave entrance. Two anonymous reviewers and the field editor contributed to improve the manuscript. 


\section{References}

Almaraz P, Amat JA (2004) Complex structural effects of two hemispheric climatic oscillators on the regional spatiotemporal expansion of a threatened bird. Ecol Lett 7: $547-556$

Béchet A, Johnson AR (2008) Anthropogenic and environmental determinants of greater flamingo Phoenicopterus roseus breeding numbers and productivity in the Camargue (Rhone delta, southern France). Ibis 150:69-79

Bosch J, Carrascal LM, Durán L, Walker S, Fisher MC (2007) Climate change and outbreaks of amphibian chytridiomycosis in a montane area of Central Spain; is there a link? Proc $\mathrm{R}$ Soc B 274:253-260

Brandimarte L, Di Baldassarre G, Bruni G, D’Odorico P, Montanari A (2011) Relation between the North-Atlantic Oscillation and hydroclimatic conditions in Mediterranean areas. Water Resour Manag 25:1269-1279

Brockwell PJ, Davies R (2002) Introduction to time series analysis and forecasting, 2nd edn. Springer, New York

Cañellas B, Orfila A, Méndez F, Álvarez A, Tintoré J (2010) Influence of the NAO on the northwestern Mediterranean wave climate. Sci Mar 75:55-64

Caruso NM, Sears M, Adams DC, Lips KR (2014) Widespread rapid reductions in body size of Appalachian salamanders in response to climate change. Glob Change Biol 20:1751-1759

Chatfield C (2004) The analysis of time series: an introduction. Chapman and Hall, London

Coulson T, Ezard THG, Pelletier F, Tavecchia G, Stenseth NG, Childs DZ, Pilkington JG, Pemberton JM, Kruuk LEB, Clutton-Brock TH, Crawley MJ (2008) Estimating the functional form for the density dependence from life history data. Ecology 89:1661-1674

Forchhammer MC, Post E (2004) Using large-scale climate indices in climate change ecology studies. Popul Ecol 46:1-12

Gordo O, Barriocanal C, Robson D (2011) Ecological impacts of the North Atlantic Oscillation (NAO) in Mediterranean ecosystems In: Vicente-Serrano SM, Trigo RM (eds) Hydrological, socioeconomic and ecological impacts of the North Atlantic Oscillation in the Mediterranean Region. Springer Science + Business Media B.V

Griffiths RA, Sewell D, McCrea RA (2010) Dynamics of a declining amphibian metapopulation: survival, dispersal and the impact of climate. Biol Conserv 143:485-491

Hairston NG (1987) Community ecology and salamander guilds. Cambridge University Press, Cambridge

Hurrell JW (1995) Decadal trends in the North Atlantic Oscillation: regional temperatures and precipitation. Science 269:676-679

Hurrell J, van Loon H (1997) Decadal variations in climate associated with the North Atlantic Oscillation. Clim Chang 36: $301-326$

Lanza B (2007) Speleomantes strinatii (Aellen, 1958) In: Lanza B, Andreone F, Bologna MA, Corti C, Razzetti E (eds) Fauna d'Italia. 42, Amphibia. Edizioni Calderini, Bologna $152-156$

Lindstrom L, Reeve R, Salvidio S (2010) Bayesian salamanders: analysing the demography of an underground population of the European plethodontid Speleomantes strinatii with state-space modelling. BMC Ecol 10:4
López-Moreno JI, Vicente-Serrano SM, Morán-Tejeda E, LorenzoLacruz J, Kenawi A, Beniston N (2011) Effects of the North Atlantic Oscillation (NAO) on combined temperature and precipitation winter modes in the Mediterranean mountains: observed relationships and projections for the 21st century. Glob Planet Chang 77:62-76

Oneto F, Ottonello D, Pastorino MV, Salvidio S (2010) Post-hatching parental care in salamanders revealed by infrared video surveillance. J Herpetol 44:649-653

Petranka JW (1998) Salamanders of the United States and Canada. Smithsonian Institution Press, Washington

Probst WN, Stelzenmüller V, Ove Fock H (2011) Using crosscorrelations to assess the relationship between time-lagged pressure and state indicators: an exemplary analysis of North Sea fish population indicators. ICES J Mar Sci 69:670-681

Quadrelli R, Pavan V, Molteni F (2001) Wintertime variability of Mediterranean precipitation and its link with large-scale circulation anomalies. Clim Dyn 17:457-466

Reading CJ (2007) Linking global warming to amphibian declines, through its effects on female body condition and survivorship. Oecologia 151:125-131

Royama T (1992) Analytical population dynamics. Chapman and Hall, London

Rubolini D, Ambrosini R, Caffi M, Brichetti P, Armiraglio S, Saino N (2007) Long-term trends in first arrival and first egg laying dates of some migrant and resident bird species in northern Italy. Int $\mathrm{J}$ Biometeorol 51:553-563

Salvidio S (1993) Life history of the European plethodontid salamander Speleomantes ambrosii. Herpetol J Lond 3:55-59

Salvidio S (2007) Population dynamics and regulation in the cave salamander Speleomantes strinatii. Naturwissenschaften 94:396-400

Salvidio S, Lattes A, Tavano M, Melodia F, Pastorino M (1994) Ecology of a Speleomantes ambrosii population inhabiting an artificial tunnel. Amphibia-Reptilia 15:35-45

Salvidio S, Romano A, Oneto F, Ottonello D, Michelon R (2012) Different season, different strategies: feeding ecology of two syntopic forest-dwelling salamanders. Acta Oecol 43:42-50

Stenseth NC, Ottersen G, Hurrell JW, Mysterud A, Lima M, Chang K-S, Yoccoz N, Ådlandsvik B (2003) Studying climate effects on ecology through the use of climate indexes: the North Atlantic Oscillation, El Niño Southern Oscillation and beyond. Proc R Soc Lond B 270: 2087-2096

Warren RJ II, Bradford MA (2010) Seasonal climate trends, the North Atlantic Oscillation, and salamander abundance in the southern Appalachian Mountain Region. J Appl Meteorol Climatol 49: $1597-1603$

Wells KD (2007) The ecology and behaviour of amphibians. Chicago University Press

White GC, Anderson DR, Burnham KP, Otis DL (1982) Capturerecapture removal methods for sampling closed populations. Los Alamos National Laboratory 8787 NERP, Los Alamos

Williams BK, Conroy MJ, Nichols JD (2001) Analysis and management of animal populations. Academic Press, San Diego

Yoccoz NG, Gaillard J-M (2006) Age structure matters for alpine ibex population dynamics: comment on Lima \& Berryman (2006). Climate Res 32:139-141

Yule GU (1926) Why do we sometimes get nonsense-correlations between time-series? A study in sampling and the nature of time-series. J R Stat Soc 89:1-63 